\title{
Double-orifice left and Ebstenoid right atrioventricular valve repair in right dominant partial atrioventricular canal defect
}

Noah Weingarten, MD, ${ }^{\mathrm{a}}$ Tara Karamlou, MD, MSc, ${ }^{\mathrm{b}}$ Munir Ahmad, MD, ${ }^{\mathrm{b}}$ Francine Erenberg, $\mathrm{MD},{ }^{\mathrm{c}}$ and Hani K. Najm, MD, MSc, ${ }^{b}$ Cleveland, Ohio

From the ${ }^{\mathrm{a} D e p a r t m e n t}$ of General Surgery, Digestive Disease \& Surgery Institute, Cleveland Clinic; and ${ }^{\mathrm{b}}$ Division of Pediatric Cardiac Surgery, Heart, Vascular, and Thoracic Institute, and ${ }^{\mathrm{c}}$ Department of Pediatric Cardiology, Cleveland Clinic Children's Hospital, Cleveland, Ohio.

Disclosures: The authors reported no conflicts of interest.

The Journal policy requires editors and reviewers to disclose conflicts of interest and to decline handling or reviewing manuscripts for which they may have a conflict of interest. The editors and reviewers of this article have no conflicts of interest.

Received for publication April 21, 2021; accepted for publication April 22, 2021; available ahead of print May 4, 2021.

Address for reprints: Tara Karamlou, MD, MSc, Division of Pediatric Cardiac Surgery, Heart, Vascular and Thoracic Institute, Cleveland Clinic, M41-022A, 9500 Euclid Ave, Cleveland, OH 44195 (E-mail: karamlt@ccf.org).

JTCVS Techniques 2021;8:172-4

2666-2507

Copyright (C) 2021 The Author(s). Published by Elsevier Inc. on behalf of The American Association for Thoracic Surgery. This is an open access article under the CC BY-NC-ND license (http://creativecommons.org/licenses/bync-nd/4.0/).

https://doi.org/10.1016/j.xjtc.2021.04.019

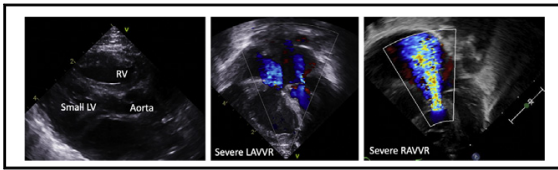

Preoperative transesophageal echocardiogram showing severe LAVVR and RAVVR.

CENTRAL MESSAGE

This report describes a set of techniques to optimize outcomes for repairs of complex atrioventricular valve defects in infants.

See Commentary on page 175 . $\square$ Video clip is available online.

Repairing complex partial atrioventricular canal (AVC) defects is challenging, particularly in infants and patients with double-orifice atrioventricular (AV) valves. ${ }^{1,2}$ We report a repair in a 6-week-old infant with partial AVC defect, severely regurgitant double-orifice left atrioventricular valve (LAVV), severely regurgitant Ebstenoid right atrioventricular valve (RAVV) with significant restriction of leaflet components, and atrial arrythmias (Video 1).

\section{CLINICAL SUMMARY}

An early-term 2.6-kg male infant with the described anatomy (Figure 1, Videos 2 and 3) was hospitalized for heart failure and inadequate oral intake. Preoperative echocardiogram showed left ventricular (LV) volume $\mathrm{z}$ scores of -2.50 in diastole and -4.20 in systole.

Through right atriotomy, the redundant right atrial wall was excised. The superior bridging leaflet (SBL) and inferior bridging leaflet (IBL) were apportioned. LAVV double orifices and leaflets were assessed. Although no valve tissue was found in the left ventricular outflow tract (LVOT) on preoperative imaging, the LVOT was assessed for tissue that could cause obstruction. Examination showed a deficient leaflet that would not produce a competent LAVV without stenosis. Therefore, patch augmentation was

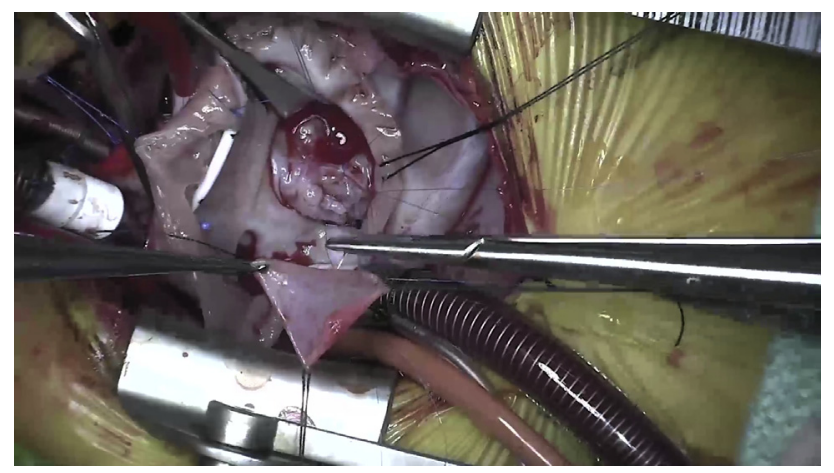

VIDEO 1. Video displaying the key techniques in a complex partial AVC repair in an infant with double orifice LAVV and significantly restricted RAVV: (1) bridging leaflet division; (2) LAVV leaflet patch augmentation with leaflet-to-leaflet apposition and commisuroplasty; and (3) RAVV subvalvular mobilization and chordal division. Video available at: https:// www.jtcvs.org/article/S2666-2507(21)00314-X/fulltext. 

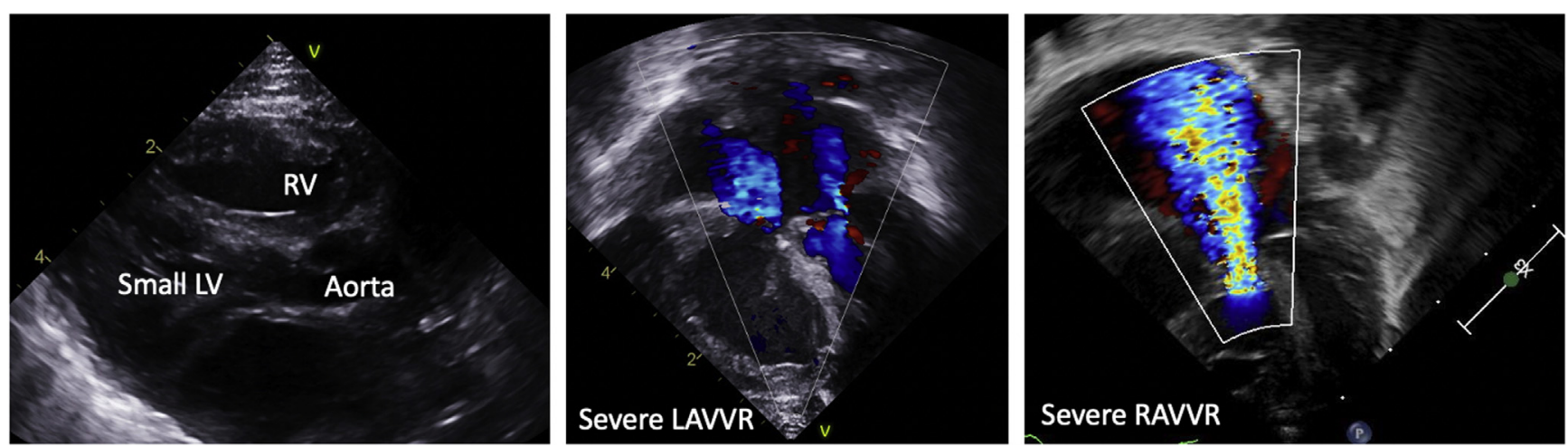

FIGURE 1. Preoperative transesophageal echocardiogram showing initial anatomy, with right-dominant unbalanced partial AVC defect, smallish left ventricle, and severe LAVVR and RAVVR. $R V$, Right ventricle; $L V$, left ventricle; $L A V V R$, left atrioventricular valve regurgitation; $R A V V R$, right atrioventricular valve regurgitation.

chosen to augment the leaflet's surface, using fresh autologous pericardium at the leaflet base as previously described. ${ }^{3}$ To enable this, the IBL was divided, allowing additional leaflet mobilization. The SBL was incised, and abnormal chords were divided, ensuring the LVOT was clear. The LAVV was sized with a Hegar dilator, aiming for one size less than expected valve size. A fresh autologous patch bridged the gap between the SBL and IBL. We were satisfied with the LAVV orifice size. The cleft was approximated. Papillary muscle mobilization under both orifices improved leaflet coaptation. Posterior suture annuloplasty of the accessory orifice was performed. Both LAVV orifices were tested and found competent. Another autologous pericardial patch was used to close the primum defect.

RAVV was assessed and found to be Ebstenoid without apical displacement. Extensive delamination of RAVV from septal muscle improved restricted leaflet movement. All chordal attachments except primary chordae were

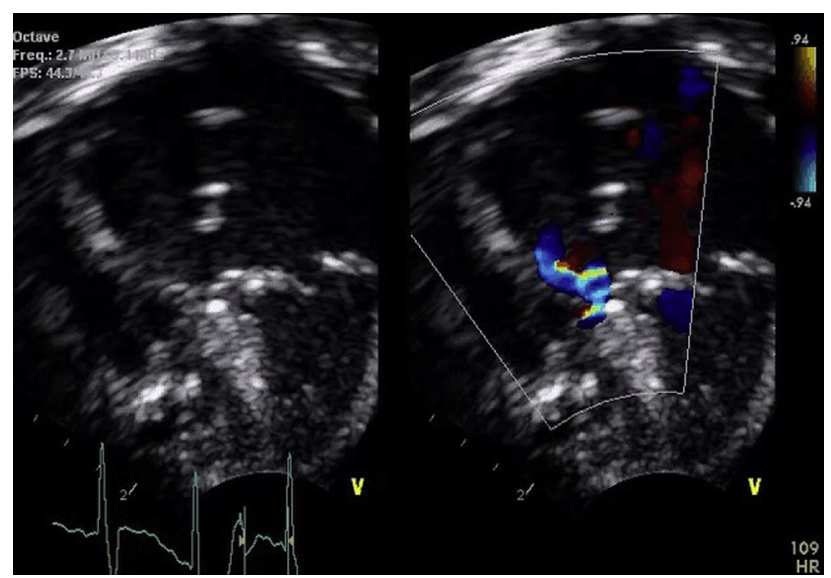

VIDEO 2. Postoperative transesophageal echo clip, apical view. Video available at: https://www.jtcvs.org/article/S2666-2507(21)00314-X/fulltext. divided. A 5-0 pledgeted ETHIBOND suture approximated papillary muscles, improving leaflet apposition. No formal leaflet rotation was performed due to poor leaflet quality. RAVV was competent.

Cut-and-sew isthmus ablation was performed with an incision from the inferior vena cava to RAVV. The right coronary artery was carefully avoided when crossing the AV groove. Cut-and-sew was chosen due to greater accuracy than cryoablation, which may freeze a substantial portion of heart in a 3-kg baby. Left atrial (LA) line placement allowed postoperative monitoring. Bypass was discontinued with good hemodynamics, but LA pressure was elevated at $17 \mathrm{~mm} \mathrm{Hg}$, and echocardiography showed moderate regurgitation of the LAVV anterolateral orifice. Bypass was reinitiated, posterior suture annuloplasty was performed on the main LAVV, and an extra cleft approximation suture was added. After weaning bypass, LA pressure was 6 to $8 \mathrm{~mm} \mathrm{Hg}$. and echocardiography showed mild LAVV regurgitation.

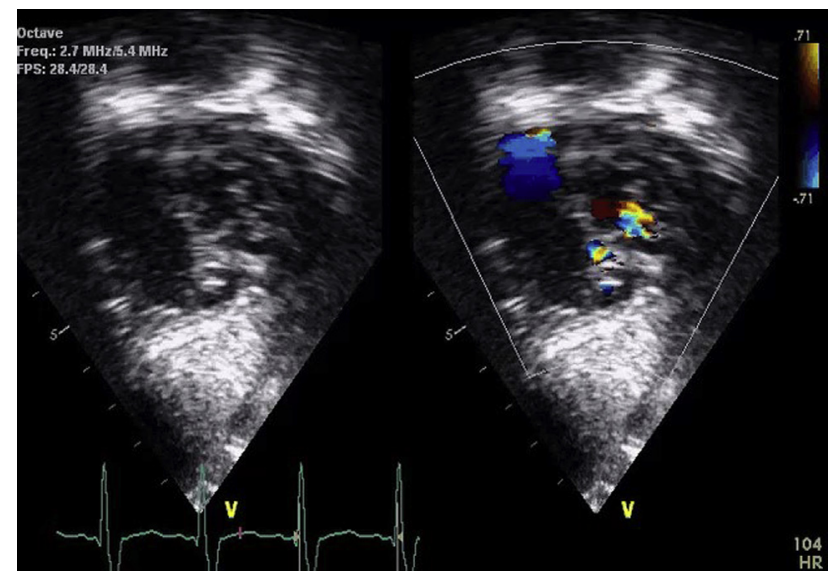

VIDEO 3. Postoperative transesophageal echo clip, short-axis view. Video available at: https://www.jtcvs.org/article/S2666-2507(21)00314$\mathrm{X} /$ fulltext. 

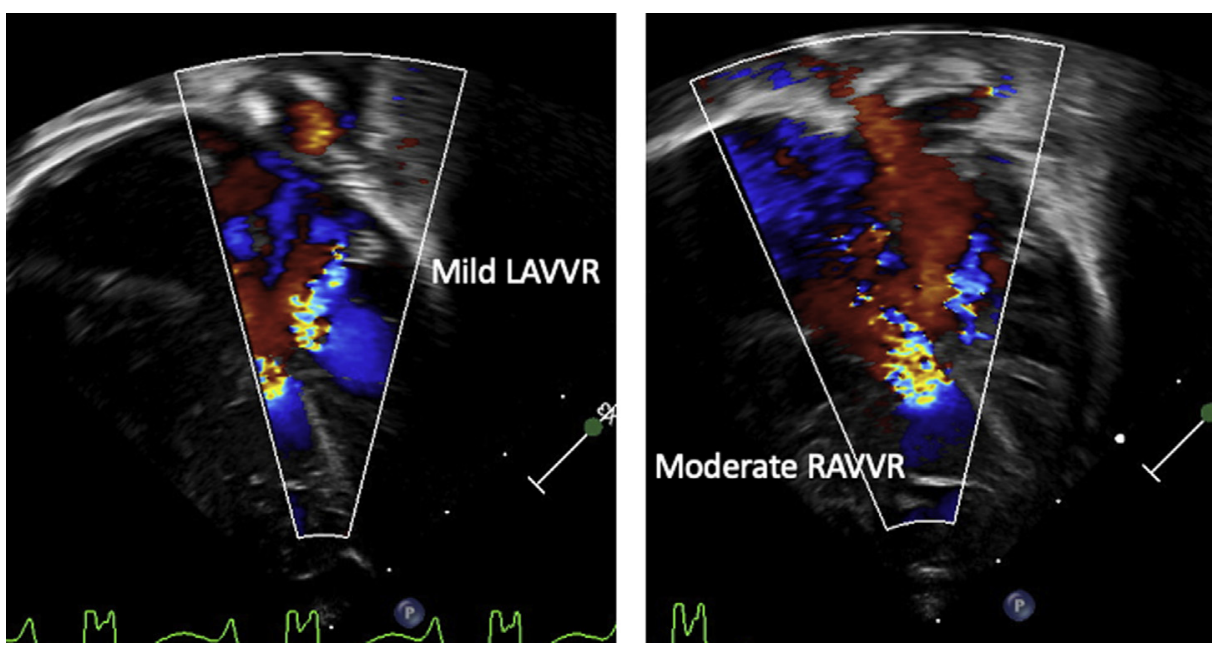

FIGURE 2. Postoperative transesophageal echocardiogram showing mild LAVVR and moderate RAVVR. LAVVR, Left atrioventricular valve regurgitation; $R A V V R$, right atrioventricular valve regurgitation.

The patient was extubated on postoperative day 8 and discharged home on room air 1 month postoperatively. Postoperative echocardiogram demonstrated mild LAVV regurgitation and moderate RAVV regurgitation (Figure 2). At 4 months, he is $4.72 \mathrm{~kg}$ with stable echocardiogram findings.

The institutional review board or equivalent ethics committee of the Cleveland Clinic did not approve this study, as review is not required for single case reports in which personal health information is not included. The subject(s) provided informed written consent for the publication of the study data.

\section{DISCUSSION}

AVC defect repair is technically challenging in the setting of severely regurgitant double-orifice LAVV, infancy, and some degree of unbalance with LV hypoplasia. While pulmonary artery banding is an option for some unbalanced partial AVC defects, its risk of worsening AVV regurgitation in patients like ours outweighs its benefits. Among patients undergoing partial and transitional AVC defect repairs, $19.2 \%$ require LAVV reoperation within 10 years, ${ }^{2}$ due primarily to LAVV regurgitation through the zone of apposition. Among patients with doubleorifice LAVV, up to $33 \%$ require reoperation, chiefly for LAVV regurgitation. ${ }^{4}$

Our report demonstrates additional techniques for accomplishing complex AV valve repair in small infants with the described anatomy who may be unsuitable for single-ventricle repair or pulmonary artery banding. Techniques used include (1) division of IBL and SBL, despite the absence of a ventricular septal defect, to allow identification of all abnormal leaflet attachments, particularly in the setting of a borderline LV with small LVOT to mitigate LVOT obstruction; (2) fresh autologous pericardial leaflet augmentation instead of direct leaflet approximation; (3) commisuroplasty for double orifice LAVV-rather than obliteration of the smaller orifice-to prevent valvular incompetence; (4) division of all valvular attachments except primary chordae to improve mobility of restricted RAVV leaflets; (5) approximation of RAVV papillary muscles with pledgeted suture to improve leaflet coaptation; and (6) LA line placement for postoperative monitoring. Postoperative care should involve avoiding hypertension, volume loading the heart, and early weaning to extubation.

\section{CONCLUSIONS}

Complex valve repairs with unbalanced partial AVC defects in infants are facilitated by a sequential approach involving all valvar components.

\section{References}

1. Pontailler M, Haidar M, Méot M, Moreau de Bellaing A, Gaudin R, Houyel L, et al. Double orifice and atrioventricular septal defect: dealing with the zone of apposition. Eur J Cardiothorac Surg. 2019;56:541-8.

2. Mery CM, Zea-Vera R, Chacon-Portillo MA, Zhang W, Binder MS, Kyle WB, et al. Contemporary results after repair of partial and transitional atrioventricular septal defects. J Thorac Cardiovasc Surg. 2019;157:1117-27.

3. Najm HK. Routine leaflet augmentation of left atrioventricular valve in the repair of atrioventricular septal defect. J Saudi Heart Assoc. 2009;21:209-13.

4. Hoohenkerk GJ, Wenink AC, Schoof PH, Koolbergen DR, Bruggemans EF, Rijlaarsdam M, et al. Results of surgical repair of atrioventricular septal defect with double-orifice left atrioventricular valve. J Thorac Cardiovasc Surg. 2009; 138:1167-71. 